\title{
Introduction of Design into a Freshmen Fundamentals of Engineering Course
}

\author{
Dr. Jonathan Smalley, P.E., Dr. Robert Ward, P.E. \\ Ohio Northern University
}

\begin{abstract}
A Fundamentals of Engineering course for all freshmen in the College of Engineering was developed in 1995. This course has evolved over its 6-year life into a 3 credit hour course taught during the fall quarter of an engineering student's initial year. The course combines lecture format and computer laboratory work using MS Word and Excel. The focus is on engineering analysis during the first half of the term and engineering design during the remainder of the quarter. The interrelationship between analysis and design is emphasized. The course also emphasizes strong oral and written communication skills in a professional setting
\end{abstract}

The students are introduced to an engineering analysis methodology through the use of "exact solution" analysis problems. Two examples of analysis problems used are part of this article. The solutions include specific formatting of the problem using word processing text, as well as advanced menus in the word processing that include a drawing editor and an equation editor. The use of a spreadsheet program is incorporated to provide ease of calculations, graphing capabilities, and some statistical analysis.

The design component of the course begins with discussions of a six-step design process. Particular emphasis is given to "constraints" on the design within the problem statement and the use of measurable "criteria" for a successful design. The choice for the best design alternative is made using a decision matrix based upon multiple design solutions and measurable criteria. Three design problems are then considered; one each in the areas of civil, electrical, and mechanical engineering. Examples of the types of design problems used are presented in the article. The class is divided into 3 or 4 person teams to perform the design. One of the three designs is chosen for completion through the construction and testing of a prototype.

The quarter concludes with each team making a professional Microsoft PowerPoint presentation on one of the design problems. Each team also writes a formal technical report for one of the other design problems. The course concludes with a student evaluation of the course outcomes and an evaluation of the course structure and methodology. The paper in no way is advocating this method of introducing design as being better than any other, but is showing a structured approach and that it works well for us.

\section{Introduction}

Ohio Northern University (ONU) is a 3250 student, United Methodist affiliated, undergraduate institution. The University has undergraduate Colleges of Arts and Sciences, Business Administration, Engineering, and Pharmacy (which graduates students with a Pharm. D. degree)

"Proceedings of the 2002 American Society for Engineering Education Annual Conference \& Exposition Copyright@2002, American Societyfor Engineering Education” 
and a College of Law. The College of Engineering has approximately 480 undergraduate students, which includes about 110 in the Civil Engineering Dept. (5 full-time faculty), 160 in the Mechanical Engineering Dept. (6 faculty), and 190 in the Electrical, Computer Engineering, and Computer Science Department ( 9 faculty). A typical freshmen class profile would show an average ACT of 26.5 with 1 in 7 being a valedictorian or salutatorian.

In the fall quarter of 1995 a Fundamentals of Engineering course for all freshmen in the College of Engineering was developed. Initially it was a team-taught 4 credit hour class with two 2-hour labs. The main topics were computer skills, problem solving, and engineering drawing. Realization came quickly that this course was labor intensive and was taking away from a student's time spent on other courses.

\section{Current Course (analysis)}

The Fundamentals of Engineering course has evolved into a 3 credit hour course with no formal lab. The course does combine lecture format and computer work using Microsoft Word and Excel. The focus is on engineering analysis during the first half of the quarter and engineering design during the remainder of the quarter. The relationship between analysis and design is emphasized. The course outcomes that were determined for the course are:

1. provide a formal definition of "Engineering

2. list and discuss aspects of engineering professionalism

3. generate solutions to analysis and design problems using an approach commonly known as the engineering method

4. use Microsoft Word to develop a technical report typical of engineering practice

5. use Microsoft Excel to develop computational solutions typical of engineering practice and to analyze and display data in appropriate format

6. use Microsoft PowerPoint to organize and present an oral technical report

During the first half of the quarter we begin by discussing the three different types of engineering problems and how each relates to the 3 components of an engineer ing problem; the input, the system, and the output. The first type is the Analysis problem in which the system component is defined, the input component is given and the resulting output component is desired. A Rating problem defines the system, the output is known and the input is needed. The Design problem is one in which the input and output are known and the best system is determined (designed). We then discuss how engineers think and work through these types of problems as compared to the sciences or the humanities ${ }^{1}$. We also discuss the definition of an engineer and what being "professional" is all about.

The students are introduced to an engineering analysis methodology through the use of "exact solution" analysis problems. A seven-step analysis procedure is taken from one of the textbooks ${ }^{2}$ for this course. The seven steps required by our students for all engineering analysis problems are: 1. Problem statement, 2. Diagram, 3. Assumptions, 4.Governing equations, 5. Calculations, 6. Solution check, and 7. Discussion. 
Two examples of analysis problems are provided in the appendix. The first, which is titled "The Bicycle Problem", is solved by hand on engineering paper. The second is "The Homerun Problem" and this is where the students are introduced to the use of a spreadsheet to assist in the analysis. Besides using the spreadsheet for its strength in doing multiple calculations the introduction to Excel also includes using its statistical package in analyzing the relationship between hand size and reach length by using the actual measurements of everyone in the class. All analysis solutions required specific formatting of the problem using MS Word and the use of advanced menus such as the drawing editor and equation editor.

The mid-term exam is given on two days. The first 50-minute exam covers the definition of engineering, types of engineering problems, unit conversion, and the working of an engineering problem using the seven-step analysis method. The second exam is on computer use (specifically Word and Excel). It emphasizes formatting, creating tables, and the use of the drawing editor and the equation editor in Word and formatting, entering equations, graph creation, and simple statistical analysis using Excel.

\section{Current Course (design)}

The subject of engineering design begins by looking at the ABET definition of design, paying particular attention to design being a decision making process that is usually iterative. Design is used to meet a desired need based upon certain constraints and desired criteria. It is emphasized that engineering analysis is just one component of engineering design.

There are many definitions for the steps involved in engineering design. The one we have chosen has six-steps and is as follows: 1. Define the problem 2. Gather information, 3 Generate viable alternative solutions, 4 . Select the best solution, 5. Implement/test, and 6. Revise/communicate ${ }^{3}$.

Defining the problem involves a problem statement, defining the variables, developing a sketch/diagram, and developing constraints/conditions that limit the viable solutions. Gathering information includes defining the existing solutions (what is right and wrong with each), developing the theory and applicable equations, listing assumptions needed, and developing measurable criteria by which the alternative solutions will be evaluated. It is emphasized that the use of engineering analysis is the major part of step 3, generating viable alternative solutions. Selecting the best solution (step 4) involves the use of a decision matrix and either the "design points method" or the "design rating method".

The design points method uses the following two equations to choose among $\mathrm{i}$ alternatives based on $\mathrm{j}$ criteria (when low scores are better): $P_{i j}=\frac{C_{j \max -} C_{i j}}{C_{j \max }-C_{j \min }}\left(P_{j}\right)$ and $P_{i}=\sum_{j=1}^{m} P_{i j}$, where $\mathrm{P}_{\mathrm{i}}$ are the total points assigned to alternative $\mathrm{i}, \mathrm{P}_{\mathrm{ij}}$ are points assigned to alternative $\mathrm{i}$ for criteria $\mathrm{j}, \mathrm{P}_{\mathrm{j}}$ are points assigned to criteria $\mathrm{j}, \mathrm{C}_{\mathrm{ij}}$ is the value of criteria $\mathrm{j}$ for alternative $\mathrm{i}, \mathrm{C}_{\mathrm{jmax}}$ is the maximum value of criteria $j$, and $C_{j m i n}$ is the minimum value of criteria $j$. The highest $P_{i}$ indicates the best solution. 
The design rating method uses the following two equations to choose among $\mathrm{i}$ alternatives based upon $\mathrm{j}$ criteria (low score is better): $R_{i j}=\frac{C_{j \max }}{C_{i j}}$ and $R_{i}=\prod_{j=1}^{m} R_{i j}$, where $\mathrm{R}_{\mathrm{i}}$ is the total rating for alternative $i, R_{i j}$ is the rating for alternative $i$ for criteria $j, C_{i j}$ is the value of criteria $j$ for alternative $i$, and $C_{j m a x}$ is the maximum value of criteria $j$. The highest $R_{i}$ indicates the best solution.

This design methodology is introduced to the freshmen class by working on a hypothetical problem such as designing a new closet for their dorm room. In groups they are asked to work through the first 3-steps of the design process with special emphasis on what "constraints" would limit possible solutions and what "criteria" should be used in the decision matrix for selecting the best solution.

Three design problems are then handed out; one problem representing each of our departments, civil, mechanical, and electrical. Examples of these 3 handouts are shown in the Appendix. As can be seen, the format of the design handout problems are based upon the six-step design process discussed earlier. In class we particularly emphasized the constraints given and why they are important as well as the criteria that was to be used in the decision matrix. We encouraged the groups to add criteria such as safety, esthetics, or ease of construction to what we gave them. We then spent at least a couple of days working through the theory used in the design and included example problems to work through first.

The first requirement as part of these design problems was to develop a decision matrix using at least six alternatives for the circuit design. Everyone had to develop this decision matrix because we then set up the actual circuits in a laboratory setting to verify our predicted results (step 5). An important realization of the students during this testing was that these light bulbs and resistors were highly variable in their output and this had to be taken into account in any design.

The groups then had three final assignments to be completed:

1. Choose 1 of the 2 remaining problems (civil or mechanical), develop a decision matrix, and determine a best alternative.

2. Choose 1 of the 3 design problems to present a professional oral presentation on during the last week of class. PowerPoint was to be used and the duration was to be between 7 and 10 minutes to include time for questions.

3. Choose 1 of the 3 design problems (other than the one used in the oral presentation) to write a technical report on and turn in during finals week. The formatting and sections of the paper were detailed to the groups.

The oral presentation directions emphasized the professional manner that was expected of all the groups as well as the professional manner of the audience. All presenters and the audience were expected to dress appropriately and the audience was expected to ask insightful questions. The technical report was expected to be taken to the Communications Skills Center for critique before turning it in.

The final exam consisted mainly of an analysis problem and a "restrictive" design problem (example in the appendix). 


\section{Conclusions}

Two evaluation tools were distributed to all students in the Fundamentals of Engineering class the last day of class. The first asked the students to evaluate the six outcomes of the course and if they "strongly agreed" or "strongly disagreed" (and 3 choices in between) that they could accomplish each outcome. For each of the outcomes, less than 5\% of the freshmen either "partially disagreed" or "strongly disagreed" that they could accomplish the outcome stated. The final exam reinforced these observations in that the design process and decision mat rix methodology were followed fairly well. What the final exam did point out was that these students need additional work in basic areas like area and volume formulas and unit conversion.

The second tool that was used to evaluate the course was general questions about the instructor, text, course structure and workload. Students felt the pace of the course was about right (although many wanted more time spent on the design process) and that the workload was a little heavier than other courses. The overall instructor rating was 4.3/5.0 and the overall estimate of the course was 3.9/5.0.

The oral presentation showed a wide range of ability to speak in front of a group (as would be expected) and it was obvious in their PowerPoint slides some groups spent much more time making them look good than other groups. However, all groups were professional is appearance and presentation.

The final written reports were surprising well done for freshmen students. Grammar and punctuation was strong and the writing was clear and to the point. The design process itself and the decision matrix were as instructed.

The design problems assigned were more restrictive than we would like for a true design. We would like to see more time spent with the students actually developing their own "constraints" and "criteria" used to set up a decision matrix. The steps in the design methodology that require constraints and beneficial criteria are sometimes the most difficult, but it is obvious that it takes design experience to make this kind of decision.

This course is a prerequisite for a second required freshman course on design. In this second three credit hour course, student teams experience the complete design process. They begin by writing proposals for design work in response to requests for proposals from the instructors. Using the concepts and design procedure from the Fundamentals of Engineering course, the teams develop, analyze, and evaluate design alternatives, construct and test a full-scale working prototype, revise and present their design.

The Fundamentals of Engineering course is not considered to be a "better" way to introduce design to freshmen, but we feel it is a unique approach to design using the concepts of constraints, criteria, and a decision matrix. The students seemed to be enthusiastic about each design problem and their evaluation of the course showed both a grasp of the methodology of design and an appreciation for the structure of the course. 


\section{Appendix}

A. Sample analysis problems:

\section{Distance traveled by a bicycle}

A bicyclist begins pedaling a bicycle from a complete stop to a constant speed. She accelerates at a constant rate until she is pedaling at 60 revolutions per minute. The biker does not achieve a constant speed until she has been pedaling for 10 minutes. The bike is geared with a 2:1 ratio, meaning that the rear wheel of the bike turns one revolution for every two revolutions of the pedals. How far does the bike travel during a 30-minute duration?

Grading of this problem will be based upon organization, use of the engineering analysis methodology, and neatness, as well as the correctness of the answer.

\section{Homerun problem}

Consider the conditions of projectile motion where an object has an initial velocity, $\mathrm{V}_{\mathrm{o}}$, directed upward at an angle of departure, $\alpha$. The velocity in the vertical direction, $V_{\text {oy }}$, is given by: $V_{\text {oy }}=V_{0} \sin (\alpha)$

while the initial velocity in the horizontal direction, $\mathrm{V}_{\mathrm{ox}}$, is given by: $V_{\text {ox }}=V_{0} \cos (\alpha)$

If the effect of air resistance is included for the velocity in the horizontal direction, $\mathrm{V}_{\mathrm{x}}$, then: $V_{x}=V_{o x} e^{-\beta t}$

where $\mathrm{e}$ is the natural $\log$ base, $\beta$ is a measure of air density, and $\mathrm{t}$ is time. The height, $\mathrm{h}$, as a function of time is given by:

$$
h=-0.5 g t^{2}+V_{o y} t+h_{o}
$$

where $g$ is the acceleration due to gravity and $h_{o}$ is the initial height. The range, $x$, as a function of time is:

$x=V_{x} t$

Create a spreadsheet, using the attached sheet as a guide, to plot height versus range for an initial velocity of $100 \mathrm{ft} / \mathrm{sec}$, angle of departure of 59 degrees, acceleration due to gravity of $32 \mathrm{ft} / \mathrm{sec}^{2}$, air resistance factor of 0.10 .

Homework Assignment: Barry Bonds has hit 63 homeruns so far this season. The speed of his bat when it hits a baseball is between 90 and 95 miles/hour. Use your spreadsheet to determine 4 combinations of bat speed and angle of departure that will produce a homerun when the 15 foot high outfield wall is 375 feet away from home plate. Enhancements to the spreadsheet would be to use a logic function to not allow $\mathrm{h}$ to be shown as negative and a results cell that would print "homerun" if the values for the parameters produce a homerun.

Produce a Word document showing the 7-step analysis method to solve this problem. Have as your Calculations section reference to your spreadsheet with a table to show your results. Use your sliding block document as an example. 
B. Sample design problems:

\section{Circuit problem}

\section{Define the Problem}

Problem Statement A lamp is to be used in an automobile application and is to be illuminated when the ignition switch is activated. The lamp, located in the instrument panel, is to be operated at less than its rated power so that it will produce subdued illumination, produce less heat, and have longer life. The lamp has a rated voltage of 2.47 volts and the current (I) and voltage (V) characteristics given in Table 1.

Table 1. I-V Characteristics of Lamp

\begin{tabular}{|c|c|}
\hline Voltage, $\mathrm{V}$, volts & Current, I, amps \\
\hline 0.000 & 0.000 \\
\hline 0.244 & 0.137 \\
\hline 0.604 & 0.161 \\
\hline 1.234 & 0.210 \\
\hline 1.640 & 0.239 \\
\hline 1.935 & 0.257 \\
\hline 2.167 & 0.271 \\
\hline 2.333 & 0.281 \\
\hline 2.473 & 0.289 \\
\hline
\end{tabular}

Design an electrical network that includes the lamp and appropriate resistors that will result in the required lamp operating conditions.

Constraints Operating power output of the lamp is to be $50 \%$ plus or minus $10 \%$ of the rated power of the lamp. The circuit must be a direct-current circuit. The energy source is the car battery of 12 volts. The power rating of each resistor used must be at least $50 \%$ greater than the actual power dissipated in the resistor.

\section{Gather Information}

Exisiting Solutions Two basic network configurations, Figure 1 and Figure 2, appear feasible and are to be included in design alternatives.

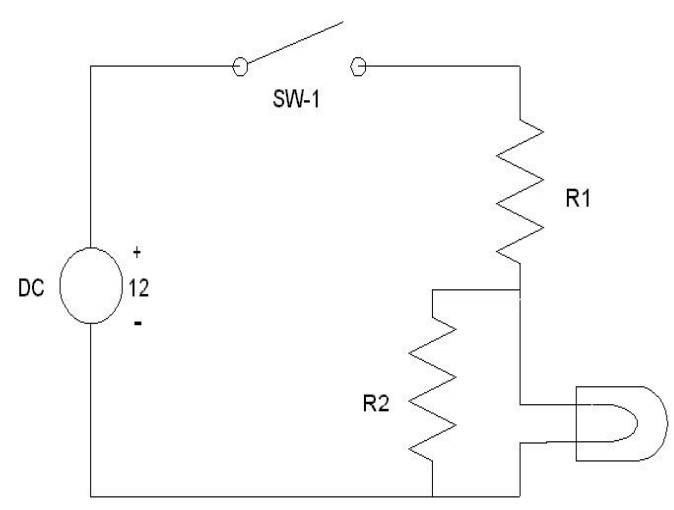

Figure 1. Circuit Configuration 1

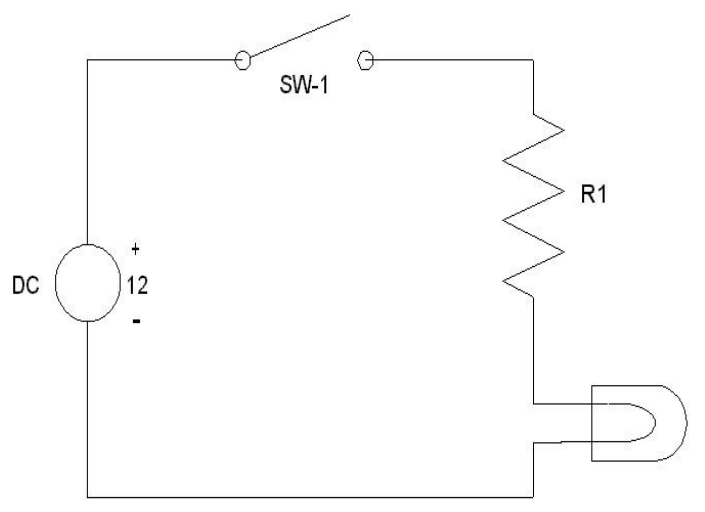

Figure 2. Circuit Configuration 2 
Theory and Applicable Equations A review of the literature related to lamps shows that the I-V characteristics of lamps are not linear, thus lamps cannot be specified in terms of resistance. The voltage across a given lamp at any particular current must be determined by taking data of current versus voltage. This relationship is given in Table 1.

Basic relations among the variables of direct current circuits are given by Ohm's Law, Kirchoff's Voltage Law, and Kirchoff's Current Law. (Sections 5.5, 5.6, and 5.7 of your text)

Criteria The following criteria must be used to select the best design from among the alternative designs:

cost

power dissipated

You may wish to consider other criteria as well.

3. Generate Viable Solutions

Develop a minimum of six alternative solutions.

\section{Select Best Solution}

Use a decision matrix to choose your design solution. Clearly indicate whether you are using the Design Points method or the Design Rating method.

\section{Implement and Test Solution}

Construct a prototype and take appropriate laboratory data to verify that your solution meets the conditions of the problem statement.

\section{Communicate the Solution}

You may choose this design assignment for your technical report. 


\section{Truss problem}

\section{Define the Problem}

Problem Statement Design a simple truss for a 40 foot span to support a 12,000 pound downward load at midspan, a 5,000 pound downward load at the left quarterspan, and an 8,000 pound downward load at the right quarterspan. The material to be used has an allowable stress of 14,000 pounds per square inch for members in tension and 6,000 pounds per square inch for members in compression. The maximum length permitted for a member in compression is 12 feet. The material weighs 400 pounds per cubic foot and costs $\$ 0.25$ per pound. Construction costs to build the truss are $\$ 1000$ per joint and $\$ 200$ plus $\$ 10$ per foot of length per member.

\section{Gather Information}

Theory A truss is a structure composed of individual straight members connected at their ends at points called joints. The overall stability of the truss is provided by two supports; one at each end of the truss. One support is called a pin support and prevents both horizontal and vertical movement. The other support is called a roller support and prevents vertical movement. External loads are applied only at the joints of the truss.

A simple truss has a geometry such that it can be "built" by starting with three members and three joints arranged as a triangle and then, sequentially, adding two additional members and one additional joint repeatedly to form the entire truss.

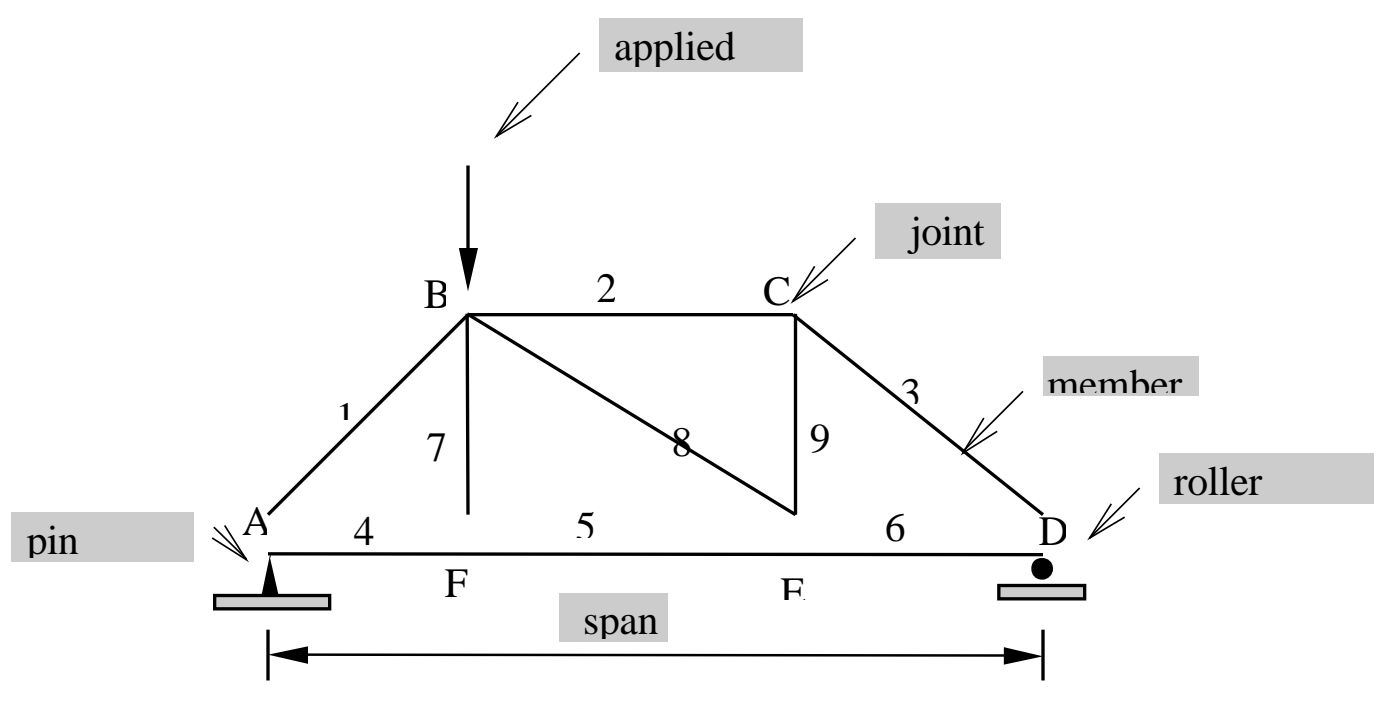

Figure 1. Example of a Simple Truss (with 9 members and 6 joints)

Externally a truss resists the applied loads by distributing the load to the supports. Internally a truss resists the applied loads by developing an internal force in each member. These internal forces may be either a tension force (tending to make the member longer) or a compression force (tending to make the member shorter). These internal forces are resisted by the member's material by developing an internal stress. 
To analyze a given truss for given loads means to determine the internal force in each member and then to ensure that the stress in each member is less than the allowable stress for that member's material.

To design a truss for given loads means to determine the geometric location of the joints and the arrangement and size of the members such that the stress in each member is less than the allowable stress.

Governing Equations (Applicable Sections of your text are 4.3, 4.4, 4.5, 4.6 and 4.7) For a simple truss with $m$ members and $j$ joints, there will be $m+3$ unknown forces: $m$ unknown internal forces in the members and 3 unknown support forces ( 1 vertical force and 1 horizontal force at the pin support; and 1 vertical force at the roller support). The relation between $\mathrm{m}$ and $\mathrm{j}$ for a simple truss is $2 \mathrm{j}=\mathrm{m}+3$.

A free body diagram of each joint can be drawn by isolating the joint from its members and replacing the members with the internal force. Any applied loads or support forces acting on the joint should also be shown. Members with internal tension forces should be replaced with a force "going away from" the joint. Members with internal compression forces should be replaced with a force "going into" the joint. These forces should be drawn in the same direction (angle) as the members that they replace. These angles can be calculated from the truss geometry.

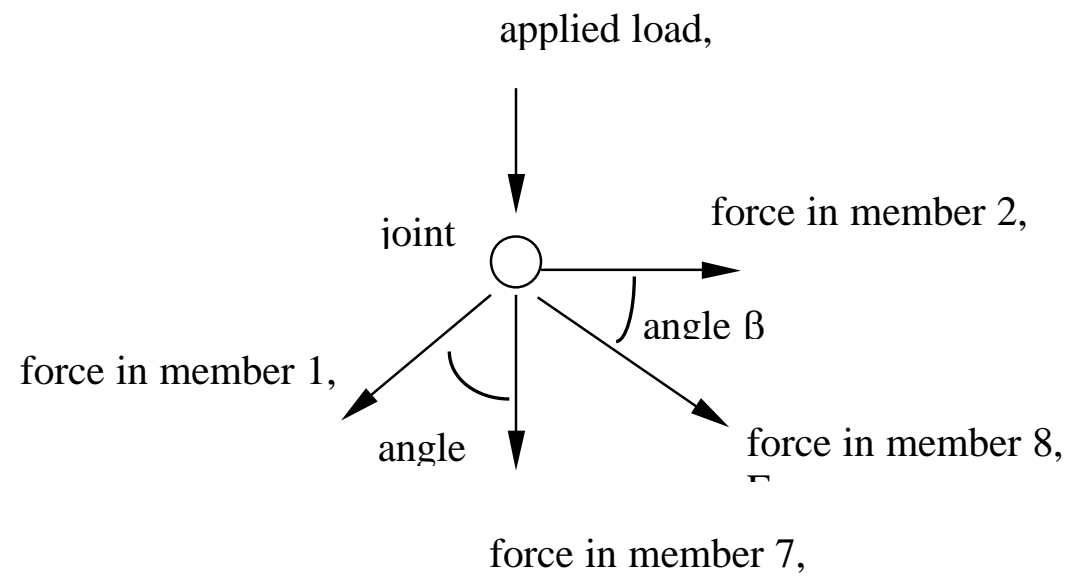

Figure 2. Free Body Diagram of Joint B of Simple Truss of Fig. 1

Usually, it is not known, ahead of time, whether a member will be in tension or compression; so assume all members, initially, to be in tension. Later, if calculations show the force to be negative, it will mean that the internal force is actually a compression force.

For a stable truss, each joint will be in equilibrium. Then according to Newton, the sum of the forces acting on the joint must be equal to zero. This is most easily applied by resolving each force into its horizontal and vertical components; then the sum of the horizontal components must be zero and the sum of the vertical components must be zero. 
For the joint shown in Figure 2 the equations are

$$
\begin{array}{ll}
\Sigma \mathrm{F}_{\text {horizontal }}=0 & \mathrm{~F}_{2}+\mathrm{F}_{8} \cos (\beta)-\mathrm{F}_{1} \sin (\alpha)=0 \\
\Sigma \mathrm{F}_{\text {vertical }}=0 & -\mathrm{P}-\mathrm{F}_{7}-\mathrm{F}_{1} \cos (\alpha)-\mathrm{F}_{8} \sin (\beta)=0
\end{array}
$$

By considering the free body diagram of each joint, the number of equations of equilibrium is $2 \mathrm{j}$ and they are in terms of the $\mathrm{m}+3$ unknown forces.

Because of the relation between $m$ and $j$ for a simple truss, the number of equations and the number of unknowns are the same. These equations can be solved simultaneously.

The stress, $\sigma$, developed by a member is the member's internal force divided by its crosssectional area, A.

Assumptions The self-weight of the truss members and joints can be neglected in comparison to the applied loads.

Criteria The following criteria must be included in those used to select the best design: cost and weight. You may wish to consider others such as safety and ease of construction.

\section{Generate Viable Solutions}

Develop a minimum of two alternative solutions each with a different geometry.

\section{Select Best Solution}

Use a decision matrix to choose your design solution. Clearly indicate whether you are using the Design Points method or the Design Rating method.

\section{Implement and Test Solution}

We will not build a prototype for this design.

\section{Communicate the Solution}

You may choose this design assignment for your technical report. 


\section{Engine problem}

1. Define the Problem Design an internal combustion engine that will deliver $75 \mathrm{~kW}$ of power. Criteria for a successful design of the engine are total engine weight, cost of operation and reliability.

2. Gather Information From the analysis of engine operation, the power $\mathrm{P}$ of an engine operating at speed $\mathrm{S}$ revolutions per unit time, mean effective pressure $\mathrm{p}$, with $\mathrm{N}$ revolutions per power stroke, and total cylinder volume $\mathrm{V}$ is given by

$$
P=\frac{V p S}{N}
$$

The total cylinder volume $\mathrm{V}$ is related to the cylinder bore $\mathrm{B}$, the stroke length $\mathrm{L}$, and the number of cylinders $n$ by

$$
V=\frac{n \pi B^{2} L}{4}
$$

The following table gives engine data for ten engines of the type you are to design although none generate exactly $75 \mathrm{~kW}$ of power.

Table 1. Representative Engine Data

\begin{tabular}{|c|c|c|c|c|c|c|}
\hline $\begin{array}{c}\text { Engine } \\
\text { Number }\end{array}$ & $\begin{array}{c}\text { Revolutions } \\
\text { per power } \\
\text { stroke, N }\end{array}$ & $\begin{array}{c}\text { Cylinder } \\
\text { Bore, B } \\
\mathrm{mm}\end{array}$ & $\begin{array}{c}\text { Stroke } \\
\text { Length, L } \\
\mathrm{mm}\end{array}$ & $\begin{array}{c}\text { Number of } \\
\text { Cylinders, } \\
\mathrm{n}\end{array}$ & $\begin{array}{c}\text { Mean } \\
\text { Effective } \\
\text { Pressure, } \\
\mathrm{p} \\
\mathrm{kPa}\end{array}$ & $\begin{array}{c}\text { Engine } \\
\text { Speed, S } \\
\text { rev/min }\end{array}$ \\
\hline 1 & 2 & 96.8 & 86 & 6 & 750 & 4300 \\
\hline 2 & 2 & 84.5 & 88 & 4 & 770 & 5200 \\
\hline 3 & 2 & 96.0 & 80 & 4 & 800 & 5000 \\
\hline 4 & 1 & 58.0 & 56 & 2 & 580 & 4500 \\
\hline 5 & 1 & 64.0 & 54 & 2 & 590 & 8200 \\
\hline 6 & 2 & 76.5 & 80 & 4 & 600 & 3200 \\
\hline 7 & 2 & 115.0 & 135 & 6 & 780 & 2500 \\
\hline 8 & 2 & 135.0 & 140 & 6 & 910 & 2300 \\
\hline 9 & 1 & 98.4 & 114 & 4 & 950 & 2500 \\
\hline 10 & 1 & 230.0 & 279 & 12 & 1000 & 900 \\
\hline
\end{tabular}

Part of the gathering of information is analysis of the available data to discover trends and to draw conclusions about relationships among variables. The average of values for a parameter and its standard deviation can be helpful. Scatter graphs of Power versus various parameters may yield trends of values. Relationships between two parameters (such as the ratio of Bore to Stroke Length) can be insightful. Sorting data by each parameter may be helpful. Each of these can lead to typical values for the parameters for a particular engine design.

3. Generate Alternative Solutions Determine at least five combinations of values for the parameters which produce the required power.

"Proceedings of the 2002 American Society for Engineering Education Annual Conference \& Exposition Copyright@2002, American Societyfor Engineering Education” 
4. Select Best Solution Use a decision matrix based on measurable values for the criteria. Total engine weight can be taken as proportional to total cylinder volume, operating cost as

proportional to mean effective pressure, and reliability as inversely proportional to engine speed.

5. Implement / Test Solution We will not build a prototype for this design.

6. Communicate the Solution. You may choose this design assignment for your technical report requirement.

C. Final Exam

Ohio Northern University

Name

College of Engineering

Section

GE 101 Fundamentals of Engineering

November 14, 2001

Final Examination

This is a two-hour closed book, closed notes examination. One $81 / 2$ " by 11 " sheet of notes is permitted. All work is to be organized, neatly presented, and solely your own. Use separate paper for your work. The weighting of each problem is as shown.

Problem 1. (40\%)

A section of steel pipe is to be filled with concrete to make a solid column. The unit weight of steel and concrete is 490 and 150 pounds per cubic foot, respectively. Determine the ratio of the outer radius to the inner radius of the pipe such that the weight of the steel and the weight of the concrete are equal. Perform steps 2 through 5 of the analysis process.

Problem 2. (50\%)

A system to move the rudder of a radio-controlled boat includes a motor, a switch circuit, and a battery. When the "control signal" closes the switch, current flows through the motor that then delivers power to the rudder. To assure motion of the rudder this power must be at least 1.0 watt. Each available battery has a rating expressed in amp-hours. Applicable equations are:

$\mathrm{I}=\mathrm{V} / \mathrm{R} \quad \mathrm{P}=\mathrm{V} \mathrm{I} \quad \mathrm{W}=\mathrm{I} \mathrm{T}$

where $\mathrm{I}$ is the current in amps

$\mathrm{V}$ is the battery voltage in volts

$\mathrm{R}$ is the equivalent motor resistance in ohms

$\mathrm{P}$ is the power in watts

$\mathrm{W}$ is the battery rating in amp-hours

$\mathrm{T}$ is the battery life in hours

You have a choice of three batteries and two motors. Any battery can be used with any motor.

\begin{tabular}{llc}
$\begin{array}{l}\text { Voltage, V } \\
\text { volts }\end{array}$ & $\begin{array}{l}\text { Ratting, W } \\
\text { amp-hrs }\end{array}$ & $\begin{array}{c}\text { Cost } \\
\$\end{array}$ \\
\hline 3 & 0.10 & 1.00 \\
6 & 0.15 & 1.50 \\
9 & 0.25 & 2.00
\end{tabular}

\begin{tabular}{cc}
\multicolumn{2}{c}{ Motor } \\
\hline $\begin{array}{l}\text { Resistance, } \mathrm{R} \\
\text { ohms }\end{array}$ & $\begin{array}{c}\text { Cost } \\
6\end{array}$ \\
\hline 0 & 3.00 \\
\hline
\end{tabular}

"Proceedings of the 2002 American Society for Engineering Education Annual Conference \& Exposition Copyright @ 2002, American Society for Engineering Education" 
Perform Steps 3 and 4 of the design process to determine the best solution for the design combination of battery and motor using the equally important criteria of total cost and battery life. Include a carefully prepared decision matrix.

Problem 3. (10\%)

For an Excel spreadsheet, if the value of $\mathrm{a}$ is in cell A1, the value of $\mathrm{b}$ is in cell $\mathrm{B} 1$, and the value of $\mathrm{c}$ is in cell $\mathrm{C} 1$, what formula should be entered into cell D1 for the expression

$$
\frac{-b+\sqrt{b^{2}-4 a c}}{2 a}
$$

Bibliography:

1. Robinson, John, "Engineering Thinking and Rhetoric," Journal of Engineering Education, July 1998

2. Hagan, K. D., Introduction to Engineering Analysis, Prentice Hall, Upper Saddle River, NJ, 2001

3. Howell, Steven, Engineering Design and Problem Solving, Benjamin/Cummings, Redwood City, CA, 1995

4. Kuncicky, D.C., Introduction to EXCEL, Prentice Hall, Upper Saddle River, NJ, 2001

\section{JONATHAN SMALLEY}

Jonathan Smalley is Professor and Chair of the Department of Civil Engineering at Ohio Northern University in Ada, Ohio. He received his Ph.D. from the Ohio State University and has taught at ONU since 1978 and has been chairman since 1993. He is a registered professional engineer in the state of Ohio. He has been a member of ASEE since 1978 and was named the ASCE Toledo Section's Engineer of the Year in 1998.

\section{ROBERT WARD}

Robert Ward is a Professor in the Department of Civil Engineering at Ohio Northern University in Ada, Ohio. He received his Ph.D. from the University of Arkansas in 1988. He has been a member of ASEE since 1987 and has been actively involved in undergraduate curriculum development since coming to ONU. He is a registered professional engineer in the states of Missouri and Ohio. .He has published articles in the fields of groundwater modeling and improving teaching of mechanics courses and has reviewed articles and texts in the areas of solid mechanics and fluid mechanics. 